\title{
Patterns of treatment and survival among older patients with stage III non-small cell lung cancer
}

Citation for published version (APA):

Driessen, E. J. M., Schulkes, K. J. G., Dingemans, A-M. C., van Loon, J. G. M., Hamaker, M. E., Aarts, M. J., \& Janssen-Heijnen, M. L. G. (2018). Patterns of treatment and survival among older patients with stage III non-small cell lung cancer. Lung Cancer, 116, 55-61. https://doi.org/10.1016/j.lungcan.2017.12.013

Document status and date:

Published: 01/02/2018

DOI:

10.1016/j.lungcan.2017.12.013

Document Version:

Publisher's PDF, also known as Version of record

Document license:

Taverne

Please check the document version of this publication:

- A submitted manuscript is the version of the article upon submission and before peer-review. There can be important differences between the submitted version and the official published version of record.

People interested in the research are advised to contact the author for the final version of the publication, or visit the DOI to the publisher's website.

- The final author version and the galley proof are versions of the publication after peer review.

- The final published version features the final layout of the paper including the volume, issue and page numbers.

Link to publication

\footnotetext{
General rights rights.

- You may freely distribute the URL identifying the publication in the public portal. please follow below link for the End User Agreement:

www.umlib.nl/taverne-license

Take down policy

If you believe that this document breaches copyright please contact us at:

repository@maastrichtuniversity.nl

providing details and we will investigate your claim.
}

Copyright and moral rights for the publications made accessible in the public portal are retained by the authors and/or other copyright owners and it is a condition of accessing publications that users recognise and abide by the legal requirements associated with these

- Users may download and print one copy of any publication from the public portal for the purpose of private study or research.

- You may not further distribute the material or use it for any profit-making activity or commercial gain

If the publication is distributed under the terms of Article $25 \mathrm{fa}$ of the Dutch Copyright Act, indicated by the "Taverne" license above, 


\title{
Patterns of treatment and survival among older patients with stage III non- small cell lung cancer
}

\author{
Elisabeth J.M. Driessen ${ }^{\mathrm{a}, \mathrm{b}, *}$, Karlijn J.G. Schulkes ${ }^{\mathrm{c}}$, Anne-Marie C. Dingemans ${ }^{\mathrm{d}}$, \\ Judith G.M. van Loon ${ }^{\mathrm{e}}$, Marije E. Hamaker ${ }^{\mathrm{f}}$, Mieke J. Aarts ${ }^{\mathrm{g}}$, Maryska L.G. Janssen-Heijnen ${ }^{\mathrm{a}, \mathrm{b}}$ \\ ${ }^{a}$ Department of Clinical Epidemiology, VieCuri Medical Centre, Venlo, The Netherlands \\ ${ }^{\mathrm{b}}$ Department of Epidemiology, Maastricht University Medical Centre+, GROW School for Oncology and Developmental Biology, Maastricht, the Netherlands \\ c Department of Pulmonology, University Medical Centre Utrecht, Utrecht, The Netherlands \\ d Department of Pulmonary Diseases, GROW School for Oncology and Developmental Biology, Maastricht University Medical Center, Maastricht, The Netherlands \\ ${ }^{\mathrm{e}}$ MAASTRO Clinic, department of radiation oncology, GROW School for Oncology and Developmental Biology, Maastricht University Medical Centre, Maastricht, The \\ Netherlands \\ ${ }^{\mathrm{f}}$ Department of Geriatric Medicine, Diakonessenhuis Utrecht, Utrecht, The Netherlands \\ ${ }^{g}$ Netherlands Cancer Registry, Netherlands Comprehensive Cancer Organisation, Utrecht, The Netherlands
}

\section{A R T I C L E I N F O}

\section{Keywords:}

Non-small cell lung cancer

Treatment

Survival

Elderly

Population-based

\begin{abstract}
A B S T R A C T
Introduction: Patterns of treatment and survival are largely unknown for older patients with stage III non-small cell lung cancer (NSCLC) in daily clinical practice.

Methods: All patients $\geq 65$ years with stage III NSCLC (2009-2013) were included from the population-based Netherlands Cancer Registry. Descriptive and multivariable treatment and survival analyses were stratified for patients aged $65-74$ years and $\geq 75$ years.

Results: Compared to older patients $(\mathrm{n}=3163)$, those aged $65-74$ years $(\mathrm{n}=3876)$ underwent more often surgery ( $21 \%$ vs $12 \%$ for stage IIIA), chemoradiotherapy ( $47 \%$ vs $22 \%$ for both stage IIIA and IIIB), and chemotherapy ( $23 \%$ vs $12 \%$ for stage IIIB), and received less radiotherapy ( $8 \%$ vs $22 \%$ for both stage IIIA and IIIB). One-year survival was significantly higher among patients aged $65-74$ compared to those aged $\geq 75$ (61\% vs $43 \%$, for stage IIIA and $45 \%$ vs $30 \%$ for stage IIIB; P < .01). However, stratification of treatment showed similar survival rates between age groups. Among patients aged 65-74 years, the multivariably adjusted hazard ratio (HR) of death was twice as high for patients receiving radiotherapy (HR 1.9 (95\%CI 1.6-2.2) for stage IIIA and HR 2.5 (95\%CI 2.1-3.0) for stage IIIB) and chemotherapy (HR 2.2 (95\%CI 1.9-2.5) and HR 2.2 (95\%CI 1.8-2.7), respectively) compared to chemoradiotherapy, and were slightly lower for patients aged $\geq 75$ years receiving radiotherapy (HR 1.6 (95\%CI 1.4-1.9) and HR 1.8 (95\%CI 1.5-2.1), respectively) and chemotherapy (HR 2.2 (95\%CI 1.8-2.7) and HR 1.8 (95\%CI 1.5-2.2), respectively). Comorbidity was not significantly associated with poorer survival ( $\mathrm{p}=.07)$.

Conclusion: Chemoradiotherapy was more often applied among patients aged 65-74 years compared to those aged $\geq 75$. While survival was worse for patients aged $\geq 75$ years, differences between age groups largely disappeared after stratification for treatment. Future research should focus on predictive patient characteristics to distinguish patients within the heterogeneous older population who can benefit from curative-intent treatment.
\end{abstract}

\section{Introduction}

Half of patients with non-small cell lung cancer (NSCLC) are aged 65 years or older at the time of diagnosis, whereas one in four is aged 75 years or older in the Netherlands [1]. Overall 5-year survival remains below $15 \%$ for patients with stage III NSCLC in daily clinical practice [2]. Concurrent chemoradiotherapy is considered standard treatment for patients with unresectable stage III NSCLC, as it results in a survival benefit of $5,7 \%$ at 3 years and $4,5 \%$ at 5 years compared to sequential chemoradiotherapy according to clinical trials [3-5]. In case

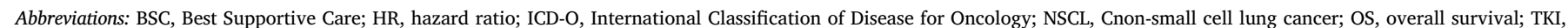
Tyrosine Kinase Inhibitor; TNM, tumour node metastasis; 95\%CI, 95\% confidence interval

* Corresponding author at: Department of Clinical Epidemiology, VieCuri Medical Centre, Venlo, The Netherlands.

E-mail addresses: ldriessen@viecuri.nl (E.J.M. Driessen), k.j.g.schulkes-2@umcutrecht.nl (K.J.G. Schulkes), a.dingemans@mumc.nl (A.-M.C. Dingemans), judith.vanloon@maastro.nl (J.G.M. van Loon), mhamaker@diakhuis.nl (M.E. Hamaker), m.aarts@iknl.nl (M.J. Aarts), mjanssenheijnen@viecuri.nl (M.L.G. Janssen-Heijnen). 
of resectable stage IIIA NSCLC, surgery with adjuvant chemotherapy is considered standard treatment [3-5],[3-5]. Older and frail patients are often excluded from clinical trials as strict eligibility criteria such as performance status, age, and strict levels of organ function are retained in order to minimize the risk of complications [6]. Elderly patients with NSCLC receive standard treatment less often [7-9]. This could be explained by a lack of evidence to extrapolate treatment guidelines to older and vulnerable patients in everyday clinical practice. Despite this lack of evidence, modest increases in the application of chemoradiotherapy were seen for older patients over time in the Netherlands [2]. A recent retrospective study from our group indicated that survival among patients with unresectable stage III NSCLC $\geq 70$ years in the southeastern part of the Netherlands was not significantly superior for those who received concurrent chemoradiotherapy as compared to sequential chemoradiotherapy and even radiotherapy alone. Also, severe comorbidity was associated with worse treatment tolerance and worse survival in case of concurrent and sequential chemoradiotherapy [10]. Therefore, it is important to assess patterns of treatment and survival in this heterogenous and older population in order to distinguish patient groups for optimal treatment strategies by patient and tumour characteristics.

The aim of this population-based study was to describe unselected patients with stage III NSCLC aged 65-74 years and those aged $\geq 75$ years regarding patterns of treatment and survival in relation with patient and tumour characteristics in the Netherlands.

\section{Methods}

All patients diagnosed with stage III NSCLC during 2009-2013 who were aged 65 years or older were retrieved from the population-based Netherlands Cancer Registry. Patients diagnosed by autopsy were not included. Since 1989, trained registrars routinely collect data from medical records regarding patient and tumour characteristics of all newly diagnosed cancer patients in the Netherlands. These data are $>$ 95\% complete and have national coverage. Vital status was retrieved from the nationwide population registries network (follow-up until February 1st 2017). This study was approved by the Privacy Review Board of the Netherlands Cancer Registry. The Central Committee on Research involving Human Subjects (CCMO) judged that approval from an ethics committee was not required.

The International Classification of Disease for Oncology (ICD-O3) $[11,12]$ was used to code topography (C34) and morphology (invasive 8010-8020, 8022-8035, 8046-8230, 8243-8246, 8250-8576, 8972,

Primary lung cancer cases assessed for eligibility between 2009 and 2013

\footnotetext{
$(\mathrm{n}=61,228)$

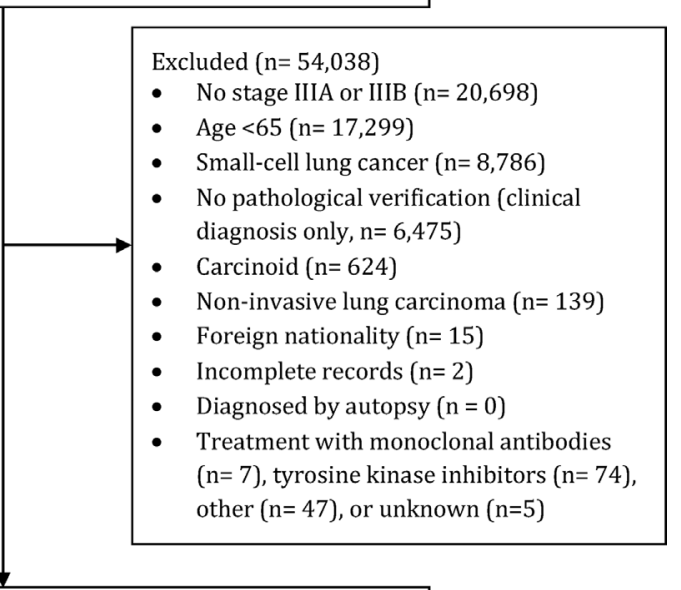

Stage III non-small cell lung cancer cases eligible for analyses $(n=7,057)^{*}$
}

8980-8982, and 9110) [13]. Diagnoses of other histologies or no pathological verfication were excluded (Fig. 1). Stage of disease was classified according to pathological Tumor Node Metastases (TNM) supplemented with clinical TNM (edition 6 up to 2009, edition 7 from 2010 onwards) [14]. The patient population was described according to two age groups (65-74 years and $\geq 75$ years). Gender, histology (adenocarcinoma, squamous cell carcinoma, large cell carcinoma and other NSCLC $^{13}$ ), and stage (IIIA and IIIB) were included in analyses. Information on comorbidity was available for patients in the southeastern part of the Netherlands only, covering approximately $15 \%$ of the Dutch population. Comorbidity was registered according to a slightly adapted version of the Charlson Comorbidity score [15]: it was classified as number of comorbid conditions $(0,1$, or $\geq 2)$, and type of comorbidity (respiratory, cardiovascular, hypertension, diabetes, previous malignancy, digestive or CVA/hemiplegia). Obtained primary treatment was categorized as surgery (including (neo)adjuvant therapy (if applicable) for stage IIIA), chemoradiotherapy (including radiotherapy with sensitizer, chemotherapy followed by radiotherapy), radiotherapy alone (both curative-intent and palliative), chemotherapy alone, and Best Supportive Care (BSC). When the time interval between treatments was available, concurrent chemoradiotherapy $(<30$ days between dates of start of both chemotherapy and radiotherapy) and sequential chemoradiotherapy ( $>30$ days between chemotherapy and radiotherapy) could be distinguished. However, time between treatments was unspecified in $22 \%$ of patients receiving chemoradiotherapy. Subanalyses were not performed for concurrent and sequential chemoradiotherapy as a large proportion of those receiving chemoradiotherapy could not be categorized. Overall survival (OS) was calculated from the time of diagnosis until death or until February 1st 2017, including median, 1year, and 3-year OS rate.

\subsection{Statistical analyses}

All analyses were performed using IBM SPSS Statistics 22.0. Stratification according to stage was consistently applied as available treatment options and prognoses differ for those with stage IIIA and IIIB NSCLC. Patient and tumour characteristics were described according to age groups, and statistical significant differences $(\mathrm{P}<0.05$ two sided) were determined by the $\mathrm{X}^{2}$-test for categorical variables and the Mannwhitney $U$ test for medians of continuous variables. OS rates were calculated for each age group, stage, and obtained treatment. OS was depicted by estimates of the Kaplan-Meier method and significant differences between treatment groups were determined by the log-rank

Fig. 1. Flow chart of eligible older patients diagnosed with stage III non-small cell lung cancer (2009-2013).

*This number can slightly deviate from the finally included number of cases as some cases could be added or excluded from the database after initial data retrieval for this study 
Table 1

Overview of patient and tumour characteristics of older patients diagnosed with stage III non-small cell lung cancer (2009-2013) according to stage and age groups.

\begin{tabular}{|c|c|c|c|c|c|c|}
\hline \multirow{2}{*}{$\begin{array}{l}\text { Stage } \\
\text { Age yrs }\end{array}$} & \multicolumn{3}{|l|}{ IIIA } & \multicolumn{3}{|l|}{ IIIB } \\
\hline & $65-74$ & $\geq 75$ & P-value & $65-74$ & $\geq 75$ & P-value \\
\hline Total N (\%) & $2160(55)$ & $1800(45)$ & & $1716(56)$ & $1363(44)$ & \\
\hline Median age yrs (IQR) & $69(67-72)$ & $79(77-82)$ & .00 & $69(67-72)$ & $79(77-82)$ & .00 \\
\hline Gender (male) \% & 67 & 75 & .00 & 69 & 73 & .04 \\
\hline \multicolumn{7}{|l|}{ Histology\% } \\
\hline Squamous CC & 46 & 52 & .00 & 42 & 44 & .00 \\
\hline Adenocarcinoma & 34 & 27 & & 35 & 28 & \\
\hline NOS/large CC & 20 & 21 & & 23 & 28 & \\
\hline \multicolumn{7}{|l|}{ Treatment * \% } \\
\hline Surgery & 21 & 12 & .00 & - & - & .00 \\
\hline Chemoradiotherapy & 47 & 24 & & 47 & 20 & \\
\hline Radiotherapy & 8 & 23 & & 8 & 22 & \\
\hline Chemotherapy & 11 & 8 & & 23 & 12 & \\
\hline BSC & 13 & 33 & & 21 & 46 & \\
\hline \multicolumn{7}{|l|}{ Comorbidity** } \\
\hline Available N (\%) & $392(57)$ & $290(43)$ & & $325(58)$ & $234(42)$ & \\
\hline \multicolumn{7}{|l|}{ Number\% } \\
\hline$\underline{0}$ & 16 & 10 & .03 & 17 & 12 & .06 \\
\hline$\underline{1}$ & 26 & 23 & & 29 & 24 & \\
\hline$\geq 2$ & 58 & 67 & & 55 & 64 & \\
\hline \multicolumn{7}{|l|}{$\overline{\text { Type } \%}$} \\
\hline Respiratory & 35 & 38 & .46 & 35 & 32 & .50 \\
\hline Cardiovascular & 47 & 58 & .00 & 44 & 58 & .00 \\
\hline Hypertension & 35 & 39 & .28 & 30 & 32 & .60 \\
\hline $\mathrm{DM}$ & 18 & 24 & .06 & 13 & 18 & .16 \\
\hline Previous malignancy & 22 & 29 & .05 & 21 & 25 & .28 \\
\hline CVA/hemiplegia & 7 & 7 & .97 & 6 & 6 & .94 \\
\hline Digestive & 6 & 9 & .21 & 7 & 12 & .07 \\
\hline
\end{tabular}

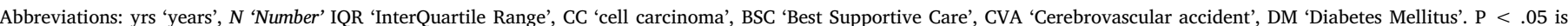

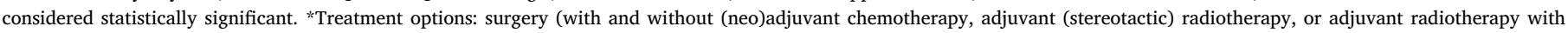

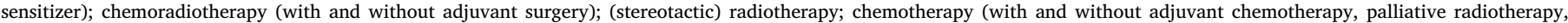

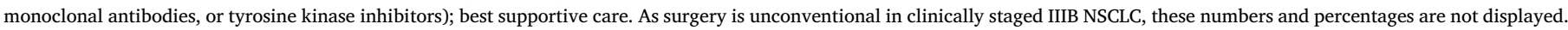
**Subanalyses of 1241 patients (18\%) with available information on comorbidity.

test $(\mathrm{P}<.05)$. Median follow-up was estimated with the reverse Kaplan-Meier method [16]. Hazard Ratios (HRs) for mortality were calculated by Cox proportional hazard regression analyses and described according to age groups. HR $>1.0$ indicated increased hazard of death. Descriptive factors were selected according to the backward stepwise likelihood ratio method and were excluded if $\mathrm{P}>.10$. The HR was adjusted for treatment, gender, age, and histology for all included patients. In addition, the cohort of the southeastern part of the Netherlands was used to investigate whether comorbidity was an important and independent predictive factor for survival. Imputation of missing values for comorbidity was not performed for patients outside the southeastern part of the Netherlands, as approximately $80 \%$ of outcomes would be imputed. Both OS rates and HRs were displayed with corresponding $95 \%$ confidence intervals $(95 \% \mathrm{CI})$. The HR was considered statistically significant when the $95 \% \mathrm{CI}$ was completely above or below 1.0.

\section{Results}

In the Netherlands, 7039 patients aged 65 years or older were diagnosed with stage III NSCLC between 2009 and 2013 (Table 1). This population covers $11 \%$ of all primary lung cancer cases in the Netherlands between 2009 and 2013, and 29\% of patients diagnosed with stage III NSCLC (Fig. 1).

Almost half of the study population was $\geq 75$ years old $(45 \%$ of stage IIIA and $44 \%$ of stage IIIB, Table 1 ). The proportion of patients with stage IIIA receiving chemoradiotherapy was significantly higher for those aged 65-74 years (47\%) compared to those aged $\geq 75$ years (24\%). The same pattern was observed for surgery ( $21 \%$ vs $12 \%$, respectively). Radiotherapy alone and BSC were offered significantly less often for those aged 65-74 years compared to patients aged $\geq 75$ years
( $8 \%$ vs $23 \%$ for radiotherapy and $13 \%$ vs $33 \%$ for BSC), while the administration of chemotherapy alone was comparable (11\% vs $8 \%)$. For stage IIIB, both age groups showed comparable proportions of chemoradiotherapy and radiotherapy alone as those with stage IIIA. However, chemotherapy alone was applied more often among patients aged $65-74$ years $(23 \%)$ compared to those aged $\geq 75$ years $(12 \%)$, while patients aged $\geq 75$ years received more BSC (46\%) than those aged $65-74$ years $(21 \%)$. Information on comorbidity was available in $18 \%$ of patients. In both stages, cardiovascular comorbidity was significantly more present among those aged 75 years or older (58\% for both stage IIIA and IIIB) compared to those aged $65-74$ years (47\% for stage IIIA and $44 \%$ for stage IIIB). Two or more comorbid conditions were significantly more present among those with stage IIIA aged $\geq 75$ years (67\%) compared to those aged 65-74 years (58\%).

Median OS, as well as 1-year, and 3-year OS were significantly higher for patients aged 65-74 years compared to those aged $\geq 75$ years $(\mathrm{P}=.00)$. However, survival rates were largely comparable between age groups after stratification for treatment in both stages (Figs. 2 and 3 , and supplemental Table 1). Outcomes of risk of death adjusted for gender, age, histology, and treatment are displayed in Table 2. Patients with stage IIIA NSCLC receiving surgery showed a decreased adjusted hazard of death compared to chemoradiotherapy (HR 0.75 (95\%CI 0.66-0.85) and HR 0.82 (95\%CI 0.68-0.987) respectively for patients aged $65-74$ years and $\geq 75$ years). The application of radiotherapy alone showed an increased hazard of death compared to chemoradiotherapy (HR 1.9 (95\%CI 1.6-2.2) and HR 1.6 (95\%CI 1.4-1.9) respectively for patients aged $65-74$ years and $\geq 75$ years), and for chemotherapy alone the HRs were the same for both age groups (HR 2.2 (95\%CI 1.9-2.5)). The highest adjusted risk of death was seen with BSC, which was more profound among patients aged 65-74 years (HR 4.8 (95\%CI 4.1-5.5)) compared to those aged $\geq 75$ years (HR 3.7 (95\%CI 
Stage IIIA
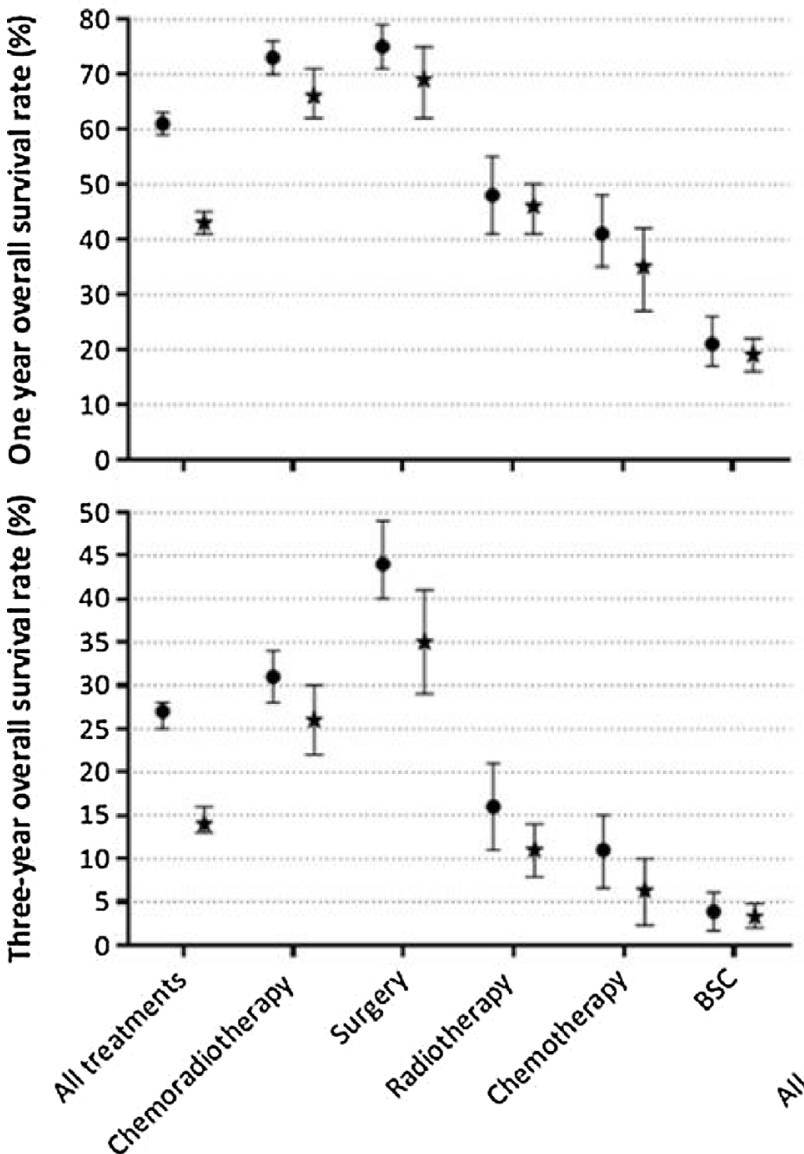

Stage IIIB
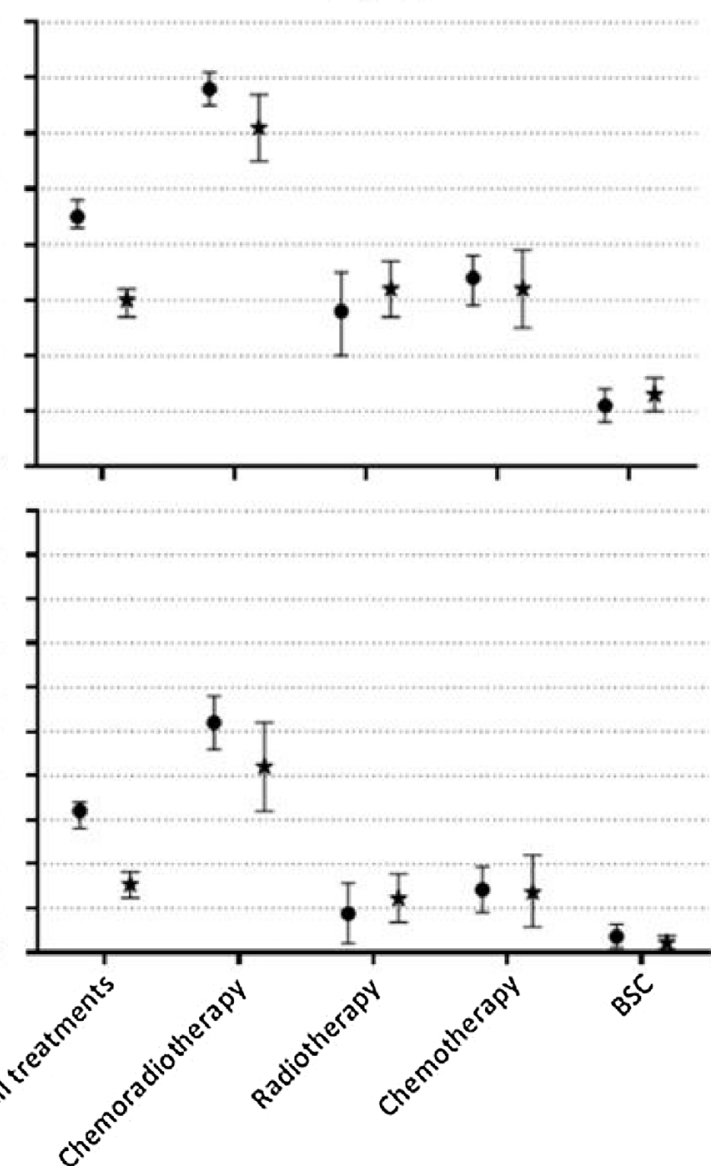

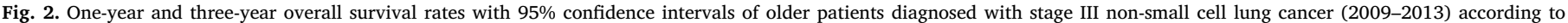
obtained treatment, stage, and age groups ( displays patients aged 65-74 years, *displays patients aged $\geq 75$ years, BSC 'best supportive care').

3.2-4.2)). For stage IIIB, adjusted hazards of death were higher after the application of radiotherapy alone (HR 2.5 (95\%CI 1.1-3.0) for patients aged 65-74 years and HR 1.8 (95\%CI1.5-2.1) for those aged $\geq 75$ years) as compared to chemoradiotherapy. The increased hazard of death was also seen for chemotherapy alone (HR 2.3 (95\%CI 2.3 (2.0-2.6) and HR 1.8 (95\%CI1.5-2.2) for age groups 65-74 years and $\geq 75$ years, respectively). The highest adjusted risk of death was seen for BSC (HR 6.2 (95\%CI 5.4-7.1) and HR 3.9 (95\%CI 3.3-4.5) for age groups $65-74$ years and $\geq 75$ years, respectively). In additional multivariable analyses including comorbidity and treatment, it was found that neither the number of comorbid conditions nor the type of comorbidity were significantly associated with survival in any age or stage group (data not shown; $\mathrm{p}=.07$ and higher). Also, changes in HRs of death for treatment types were minimal when comorbidity was included.

\section{Discussion}

The aim of this study was to assess patterns of treatment and survival among unselected Dutch patients with stage III NSCLC by describing patients aged $65-74$ years and those aged $\geq 75$ years. Almost half of patients aged 65-74 years received chemoradiotherapy, while this was only one fifth among those aged $\geq 75$ years. Higher survival rates were seen for patients aged 65-74 years compared to those aged $\geq 75$ years, although differences between age groups largely disappeared after stratification for treatment. In both age groups, survival after radiotherapy alone, chemotherapy alone, or BSC was poorer than after the application of chemoradiotherapy or surgery with larger differences for multivariable risk of death among patients aged 65-74 years than those aged $\geq 75$ years.

Patients with NSCLC are widely recognized as a heterogeneous population, especially in case of older age [17]. Although older age alone should not be decisive for treatment decision-making, patient preferences are equally important as high-risk factors such as comorbidity, poor performance status, inactivity, malnutrition, or cognitive impairment $[10,18,19]$. The results of the current study confirmed that curative-intent treatment options such as chemoradiotherapy and surgery were selected in half of those aged 65-74 years and for $19 \%-35 \%$ of patients aged $\geq 75$ years. Also, patients aged $\geq 75$ years showed poorer survival compared to those aged 65-74 years in general, although survival rates were largely comparable between age groups within treatment options. While adjustment for comorbidity was performed, residual bias due to higher natural mortality rates in older patients might be of influence, as adjusting for natural mortality could lead to even lower differences in (relative) survival between age groups. Nevertheless, these findings suggest that strict but feasible selection criteria are currently applied for intensive treatment options in clinical practice. Nevertheless, current criteria could be too strict, leading to a suboptimal number of patients aged $\geq 75$ years receiving chemoradiotherapy or surgery. Previous studies indicated that signs of vulnerability including performance status and comorbidity lead to omission of concurrent chemoradiotherapy in two thirds of those aged $\geq 70$ years [7] and almost all aged $\geq 75$ years, [20,21] which is possibly due to awareness of adverse events. However, overtreatment should also be avoided. As unplanned hospitalizations, and not completing treatment are common for chemoradiotherapy [10], especially for older patients compared to younger patients [20]. The added survival value due to intensive treatment could be less for patients aged $\geq 75$ years than for 


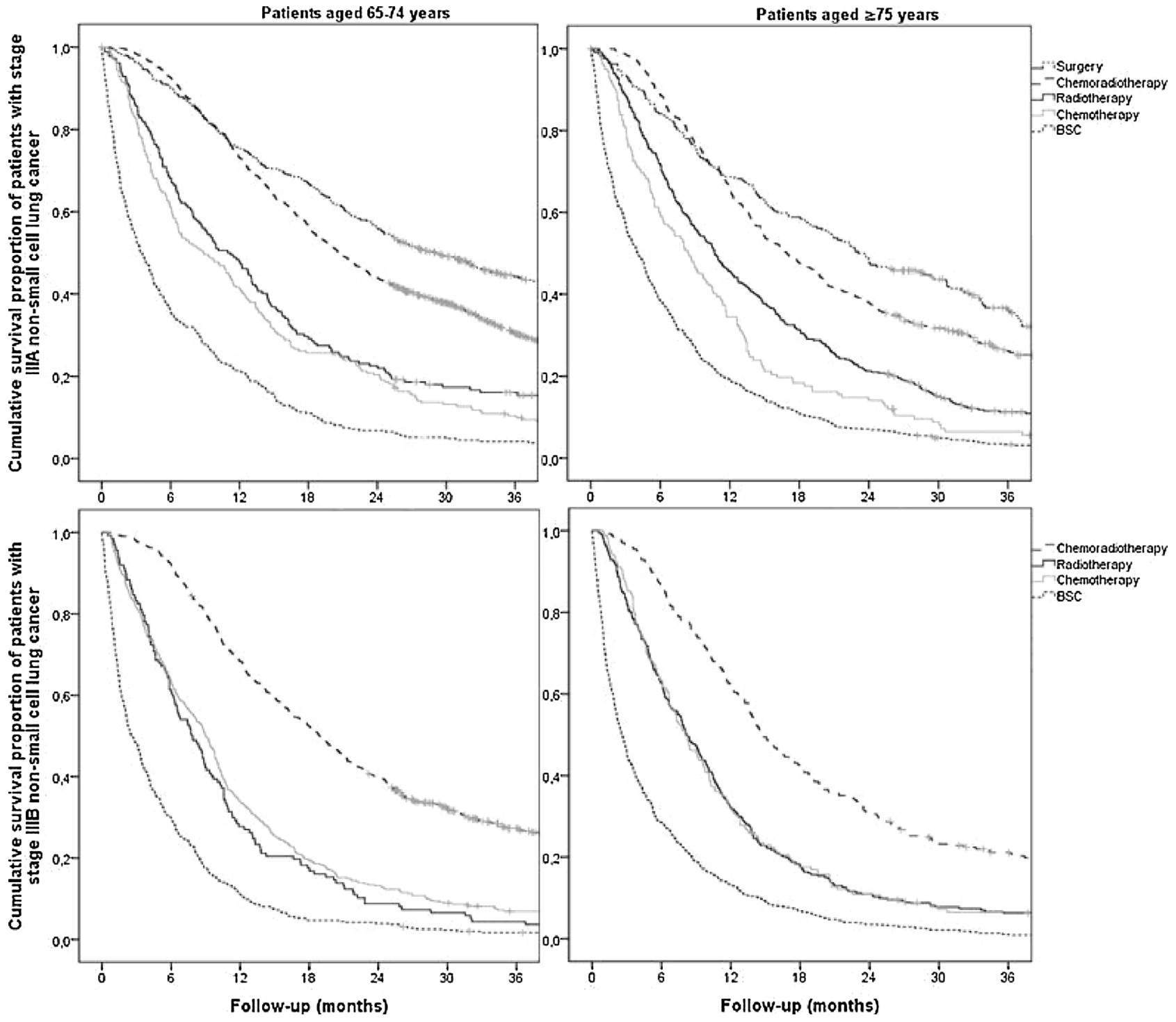

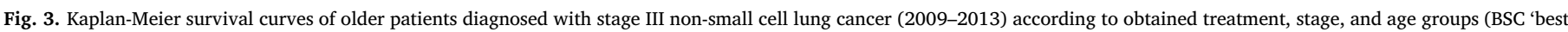
supportive care').

Table 2

Multivariable cox proportional hazard ratios of older patients diagnosed with stage III non-small cell lung cancer (2009-2013) according to stage and age groups.

\begin{tabular}{|c|c|c|c|c|c|}
\hline \multirow{2}{*}{$\begin{array}{l}\text { Stage } \\
\text { Age yrs }\end{array}$} & \multirow[b]{2}{*}{ HR (95\%CI) } & \multicolumn{2}{|l|}{ IIIA } & \multicolumn{2}{|l|}{ IIIB } \\
\hline & & $65-74$ & $\geq 75$ & $65-74$ & $\geq 75$ \\
\hline \multirow[t]{5}{*}{ Treatment** } & Chemoradiotherapy & Ref & Ref & Ref & Ref \\
\hline & Surgery & $0.75(0.66-0.85)$ & $0.82(0.68-0.987)$ & - & - \\
\hline & Radiotherapy & $1.9(1.6-2.2)$ & $1.6(1.4-1.9)$ & $2.5(2.1-3.0)$ & $1.8(1.5-2.1)$ \\
\hline & Chemotherapy & $2.2(1.9-2.5)$ & $2.2(1.8-2.7)$ & $2.3(2.0-2.6)$ & $1.8(1.5-2.2)$ \\
\hline & BSC & $4.8(4.1-5.5)$ & $3.7(3.2-4.2)$ & $6.2(5.4-7.1)$ & $3.9(3.3-4.5)$ \\
\hline Age & yrs & $1.02(0.999-1.03)$ & NA & NA & NA \\
\hline \multirow[t]{2}{*}{ Gender } & Male & Ref & Ref & NA & NA \\
\hline & Female & $0.87(0.79-0.96)$ & $0.86(0.77-0.96)$ & & \\
\hline \multirow[t]{3}{*}{ Histology } & Squamous CC & Ref & Ref & Ref & NA \\
\hline & Adenocarcinoma & $0.86(0.77-0.96)$ & $0.87(0.77-0.98)$ & $0.72(0.65-0.82)$ & \\
\hline & NOS/large CC & $0.98(0.87-1.1)$ & $0.95(0.84-1.1)$ & $0.91(0.80-1.03)$ & \\
\hline
\end{tabular}

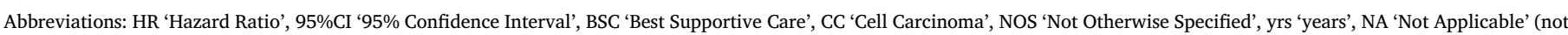

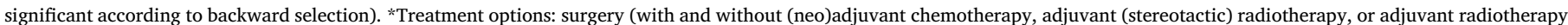

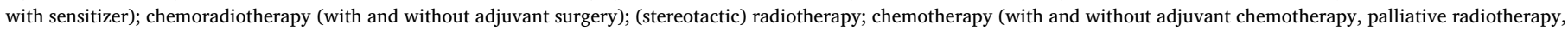

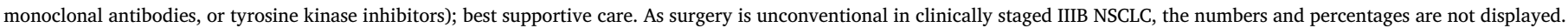
The HR is considered significant when the $95 \% \mathrm{CI}$ is completely above or below 1.0 , with $\mathrm{HR}>1.0$ indicating increased hazard of death. 
those aged 65-74 years, as the increased risks of death for other treatment options were less pronounced in the older age group. Severe comorbidity could significantly deteriorate treatment tolerance and survival in patients receiving concurrent chemoradiotherapy [10,21]. This was not confirmed by the current study and could be explained by the classification of comorbidity. The Adult Comorbidity Evaluation with 27 items (ACE-27) is used more often for cancer research and includes a time window of events and severity of organ decompensation, providing more insight in effects of treatment and consequently information for future treatment decision making [22,23]. Others implicate that collineairity and greater impact of other factors such as performance status or the likeliness of dying due to NSCLC can limit the effect of comorbidity on survival $[8,24]$.

Strengths of this study were the population-based design and inclusion of (practically) all patients diagnosed with stage III NSCLC between 2009 and 2013 in the Netherlands. The added value of these results to current knowledge lies in the presentation of obtained treatment and survival rendering for unselected elderly in clinical practice. Also, access to health care is equal for all citizens in the Netherlands and all costs regarding medical treatment for NSCLC are reimbursed. As the registrars at the Netherlands Cancer Registry are trained for data collection, the quality and completeness of data is very high.

Nevertheless, some limitations should be considered. Patient information regarding performance status, smoking, social situation, and geriatric characteristics was largely unavailable, and could lead to unknown biases. Information on number and type of comorbid conditions was only available in $18 \%$ of patients. Nevertheless, all patients in the Netherlands were included, providing insights in unselected older patients. While the availability of data on treatment is unique in such a large population-based database, some treatment details were largely unavailable, such as completion of treatment, toxicity, type of chemotherapy, type of radiotherapy, treatment doses, treatment intent, and time between treatments. Unfortunately, concurrent and sequential chemoradiotherapy could not be distinguished for all patients. The rather high proportion of patients diagnosed with (clinical) stage IIIB receiving chemotherapy can be explained by retrieval of obtained treatment. As toxicity data are unavailable, it is possible that chemoradiotherapy was planned while toxicities inhibited the administration of radiotherapy or further treatment. As a result, treatment of these patients was classified as chemotherapy leading to a higher proportion of patients receiving chemotherapy instead of (intended) chemoradiotherapy in clinical practice [10]. Furthermore, a minor proportion of patients diagnosed with 'wet' stage IIIB in 2009 (TNM6, stage IIIB NSCLC with malignant pleural effusion) are more likely to be treated with chemotherapy alone. Also, effects of chemotherapy could be minimal due to the aggressiveness of disease. Despite a median followup of $\geq 5$ years, most patients receiving surgery and chemoradiotherapy were censored after 24 months. Although this is an appropriate follow-up time, long-term survival in these treatment groups could potentially be higher when a longer follow-up period could be taken into account. In population-based studies, the best suitable treatment option is chosen by a multidisciplinary tumour board together with the patient and ideally based on a complex interplay of patient, tumour, and geriatric factors influencing which individually can influence treatment ouctomes as well [24]. As a result, confounding by indication should be considered when interpreting data on treatment, as merely fit patients would be considered for chemoradiotherapy according to treatment guidelines [3]. Furthermore, these data are retrospective and causal relations between patient characteristics and survival could not be examined.

Evidence regarding tools for treatment selection and optimization of survival, adverse events, and quality of life are currently lacking among older patients with stage III NSCLC in clinical practice. In this heterogeneous population including the oldest and frail subgroups, more insight could be gained through geriatric assessment, where important areas of vulnerability and potential effects of treatment are covered. While evidence is relatively scarce, it is recommended for several groups of older (lung) cancer patients [19,25], but not yet part of standard treatment everywhere [26,27]. With this information, relevant matters regarding treatment selection of intensive options can be improved including lifestyle interventions [28]. Ideally, clinical trials should be performed to assess the predicitive value of multiple factors including geriatric information and contribute to evidence of the most optimal treatment option for each patient [29]. However, evidence for treatment selection is largely unavailable for patients in clinical practice, as almost $90 \%$ of older patients with lung cancer is excluded due to strict in- or exclusion criteria leading to an unrepresentative population [6]. As trials are not always suitable for older patients due to slow accrual and inclusion of selected patients only [6], other study types should be considered as well. National prospective population-based studies with long-term follow-up and abundant information on patient characteristics and outcomes in clinical practice could provide more insight into current practice, information gaps, and directions for future research. Also, some form of geriatric assessment and measurement of quality of life should be included.

Recently, the NVALT25-ELDAPT trial (NCT02284308) has started $[27,30]$, combining an observational and randomized design. Here it is aimed to improve individual treatment choices for patients with stage III NSCLC $\geq 75$ years by reaching the optimal balance between quality of life and survival. All included patients receive extensive geriatric assessment and are classified as 'fit' or 'frail', where fit patients are invited to be randomized to concurrent or sequential chemoradiotherapy. Frail or fit patients without additional consent receive treatment according to the physician's discretion and patient preferences, representing patients in daily clinical practice. The primary outcome of both groups is quality-adjusted survival (http://www. eldapt.org/). With these initiatives, highly needed scientific evidence addressing predictive factors in a large heterogeneous population will contribute to optimizing treatment selection and outcomes.

In conclusion, patients aged $\geq 75$ years with stage III NSCLC were less frequently treated with chemoradiotherapy and surgery as compared to patients aged 65-74 years. Although OS rates were significantly poorer for those aged $\geq 75$ years in general, these were largely comparable between age groups within treatment options. Therefore, treatment selection seems to be adequate for the older population with stage III NSCLC, although undertreatment of the oldest group should be warranted. Evidence regarding tools to distinguish patients fit enough for chemoradiotherapy or surgery are necessary to optimize treatment selection, survival, adverse events, and quality of life for the heterogeneous group patients with stage III NSCLC aged $65-74$ years and especially $\geq 75$ years in daily clinical practice.

\section{Conflicts of interest}

None declared.

\section{Acknowledgements}

We would like to thank the registrars at the Netherlands Cancer Registry and participating hospitals for the collection of patient data. In addition, we would like to thank the Aart Huisman Scholariship for Research in Geriatric Oncology.

\section{Appendix A. Supplementary data}

Supplementary data associated with this article can be found, in the online version, at https://doi.org/10.1016/j.lungcan.2017.12.013.

\section{References}

[1] Netherlands Cancer Registry, Incidence of Non-small Cell Lung Cancer in the 
Netherlands According to Five-year Age Groups (2005-2015), Comprehensive Cancer Center the Netherlands (IKNL), 2016 Available from: http://

cijfersoverkanker.nl/selecties/dataset_3/img572754f344c02.

[2] E.J. Driessen, M.J. Aarts, G.P. Bootsma, J.G. van Loon, M.L. Janssen-Heijnen, Trends in treatment and relative survival among non-small cell lung cancer patients in The Netherlands (1990-2014): Disparities between younger and older patients, Lung Cancer 108 (2017) 198-204.

[3] W.E.E. Eberhardt, D. De Ruysscher, W. Weder, C. Le Péchoux, P. De Leyn, H. Hoffmann, et al., 2nd ESMO consensus conference in lung cancer: locally advanced stage III non-small-cell lung cancer, Ann. Oncol. 26 (8) (2015) 1573-1588.

[4] A. Aupérin, C. Péchoux Le, E. Rolland, W.J. Curran, K. Furuse, P. Fournel, et al., Meta-analysis of concomitant versus sequential radiochemotherapy in locally advanced non-small-cell lung cancer, J. Clin. Oncol. 28 (13) (2010) 2181-2190.

[5] Dutch National Working Group on Lung Tumours, Non-small Cell Lung Cancer, National Guidelines, (2015) Available from: www.oncoline.nl.

[6] K.J.G. Schulkes, C. Nguyen, F. van den Bos, L.J.R. van Elden, M.E. Hamaker, Selection of patients in ongoing clinical trials on lung cancer, Lung 194 (6) (2016) 967-974.

[7] S. Semrau, H. Zettl, G. Hildebrandt, G. Klautke, R. Fietkau, Older patients with inoperable non-small cell lung cancer, Strahlenther. Onkol. 190 (12) (2014) $1125-1132$

[8] A. Mellemgaard, M. Lüchtenborg, M. Iachina, E. Jakobsen, A. Green, M. Krasnik, et al., Role of comorbidity on survival after radiotherapy and chemotherapy for nonsurgically treated lung cancer, J. Thorac. Oncol. 10 (2) (2015).

[9] O.S. Glotzer, T. Fabian, A. Chandra, C.T. Bakhos, Non-small cell lung cancer therapy: safety and efficacy in the elderly Drug, Healthcare Patient Saf. 5 (2013) 113-121.

[10] E.J.M. Driessen, G.P. Bootsma, L.E.L. Hendriks, F.W.P.J. van den Berkmortel, B.A.H.A. Bogaarts, J.G.M. van Loon, et al., Stage III non-small cell lung cancer in the elderly: patient characteristics predictive for tolerance and survival of chemoradiation in daily clinical practice, Radiother. Oncol. 121 (October (1)) (2016) $26-31$.

[11] WHO, International Classification of Diseases for Oncology, third edition, (2000).

[12] WHO, Updates to the International Classification of Diseases for Oncology, third edition, (2012).

[13] A. Fritz, C. Percy, A. Jack, K. Shanmugaratnam, L. Sobin, D. Parkin, et al., International Classification of Diseases for Oncology (ICD-O), 3rd edition, World Health Organization, 2013 1st revision.

[14] S. Mirsadraee, D. Oswal, Y. Alizadeh, A. Caulo, E.J.R. van Beek, The 7th lung cancer TNM classification and staging system: review of the changes and implications, World J. Radiol. 4 (4) (2012) 128-134.

[15] M.E. Charlson, P. Pompei, K.L. Ales, C.R. MacKenzie, A new method of classifying prognostic comorbidity in longitudinal studies: development and validation, J. Chronic Dis. 40 (5) (1987) 373-383.

[16] M. Schemper, T.L. Smith, A note on quantifying follow-up in studies of failure time,
Control. Clin. Trials 17 (4) (1996) 343-346.

[17] R. Blanco, I. Maestu, M.G. de la Torre, A. Cassinello, I. Nuñez, A review of the management of elderly patients with non-small-cell lung cancer, Ann. Oncol. 26 (March (3)) (2015) 451-463.

[18] C. Kenis, D. Bron, Y. Libert, L. Decoster, K. Van Puyvelde, P. Scalliet, et al., Relevance of a systematic geriatric screening and assessment in older patients with cancer: results of a prospective multicentric study, Ann. Oncol. 24 (5) (2013) 1306-1312.

[19] K.J.G. Schulkes, M.E. Hamaker, F. van den Bos, L.J.R. van Elden, Relevance of a geriatric assessment for elderly patients with lung cancer - a systematic review, Clin. Lung Cancer 17 (5) (2016) 341-349 (e3).

[20] O. Hansen, T. Schytte, M. Nielsen, C. Brink, Age dependent prognosis in concurrent chemo-radiation of locally advanced NSCLC, Acta Oncol. 54 (3) (2015) 333-339.

[21] J. Nilsson, A. Berglund, S. Bergström, M. Bergqvist, M. Lambe, The role of comorbidity in the management and prognosis in nonsmall cell lung cancer: a population-based study, Acta Oncol. 56 (7) (2017) 949-956.

[22] M.A. Gosney, Clinical assessment of elderly people with cancer, Lancet Oncol. 6 (10) (2005) 790-797.

[23] D. Kallogjeri, J.F. Piccirillo, E.L. Spitznagel, E.W. Steyerberg, Comparison of scoring methods for ACE-27: simpler is better, J. Geriatr. Oncol. 3 (3) (2012) 238-245.

[24] M.C. Brouwers, J. Makarski, K. Garcia, S. Akram, G.E. Darling, P.M. Ellis, et al., A mixed methods approach to understand variation in lung cancer practice and the role of guidelines, Implement. Sci.: IS 9 (2014) 36.

[25] H. Wildiers, P. Heeren, M. Puts, E. Topinkova, M.L.G. Janssen-Heijnen, M. Extermann, et al., International society of geriatric oncology consensus on geriatric assessment in older patients with cancer, J. Clin. Oncol. 32 (24) (2014) 2595-2603.

[26] E. Driessen, J. van Loon, H. Maas, A.-M. Dingemans, MLGJ-H, Geriatric Assessment for Older Patients with Non-small Cell Lung Cancer: Daily Practice of Centers Participating in the NVALT25-ELDAPT Trial, (2017) (unpublished).

[27] E. Driessen, M. Janssen-Heijnen, H. Maas, A.-M. Dingemans, J. Van Loon, Study Protocol of the NVALT25-ELDAPT Trial: Selecting the Optimal Treatment for Older Patients with Stage III Non-small Cell Lung Cancer, (2017) (unpublished).

[28] B.C. Bade, D.D. Thomas, J.B. Scott, G.A. Silvestri, Increasing physical activity and exercise in lung cancer: reviewing safety, benefits, and application, J. Thorac. Oncol. 10 (6) (2015) 861-871.

[29] R. Corre, L. Greillier, H. Le Caër, C. Audigier-Valette, N. Baize, H. Bérard, et al., Use of a comprehensive geriatric assessment for the management of elderly patients with advanced non-small-cell lung cancer: the phase III randomized ESOGIA-GFPCGECP 08-02 study, J. Clin. Oncol. 34 (13) (2016) 1476-1483.

[30] J.G.M. Van Loon, A.-M.C. Dingemans, M.L.G. Janssen-Heijnen, H. Maas, ELDAPTElderly with Locally Advanced Lung Cancer: Deciding Through Geriatric Assessment on the oPtimal Treatmentstrategy, (2016) Available from: http://www. eldapt.org/. 